\title{
Wellbeing, Whole Health and Societal Transformation: Theoretical Insights and Practical Applications
}

\author{
Andrew H Kemp, PhD, DH-SC Melb ${ }^{1,2}$ (1) and Zoe Fisher, PhD, DClinPsy Card ${ }^{2,3} \odot$
}

\begin{abstract}
Society faces several major interrelated challenges which have an increasingly profound impact on global health including inequalities, inequities, chronic disease and the climate catastrophe. We argue here that a focus on the determinants of wellbeing across multiple domains offers under-realised potential for promoting the 'whole health' of individuals, communities and nature. Here, we review recent theoretical innovations that have laid the foundations for our own theoretical model of wellbeing - the GENIAL framework - which explicitly links health to wellbeing, broadly defined. We emphasise key determinants across multiple levels of scale spanning the individual, community and environmental levels, providing opportunities for positive change that is either constrained or facilitated by a host of sociostructural factors lying beyond the immediate control of the individual (e.g. social cohesion and health-related inequities can either promote or adversely impact on wellbeing, respectively). Following this, we show how the GENIAL theoretical framework has been applied to various populations including university students and people living with neurological disorders, with a focus on acquired brain injury. The wider implication of our work is discussed in terms of its contribution to the understanding of 'whole health' as well as laying the foundations for a 'whole systems' approach to improving health and wellbeing in a just and sustainable way.
\end{abstract}

\section{Keywords}

whole health, wellbeing, health care, education, planetary wellbeing

Received August 17, 202I. Accepted for publication December 22, 2021

\section{Introduction}

Wellbeing causally affects health and longevity after controlling for health and socioeconomic status at baseline. ${ }^{1}$ At a biological level, there is now compelling evidence for the interconnectedness of pathways subserving physical and mental health. ${ }^{2,3}$ Therefore, discussions about 'whole health' are wholly inadequate without the inclusion of wellbeing. The aim of this article is to highlight the importance of wellbeing towards 'whole health' by introducing theoretical insights from wellbeing science, including our own work. We then describe how we have applied this theory within the healthcare and education sectors in the UK, which in turn have helped to further clarify key concepts of our framework. Guided by social ecological theory, ${ }^{4,5}$ we argue for a more inclusive approach to whole health that encompasses

\footnotetext{
'School of Psychology, Faculty of Medicine, Health \& Life Science, Swansea University, Swansea, UK

${ }^{2}$ Regional Neuropsychology and Community Brain Injury Service, Morriston Hospital, Swansea UK

${ }^{3}$ Health and Wellbeing Academy, Faculty of Medicine, Health \& Life Science, Swansea University, Swansea, UK

Corresponding Author:

Andrew H Kemp and Zoe Fisher, School of Psychology, Faculty of Medicine, Health \& Life Science, Swansea University, Singleton Campus, Singleton Park, Swansea SA2 8PP, UK; Regional Neuropsychology and Community Brain Injury Service, Morriston Hospital, Swansea UK; Health and Wellbeing Academy, Faculty of Medicine, Health \& Life Science, Swansea University, Old Creche Building, Morriston Hospital, Morriston, Swansea SA6 6NL, UK.

Email: a.h.kemp@swansea.ac.uk; Zoe.Fisher4@wales.nhs.uk
} 
concepts of individual, collective and planetary wellbeing and their interconnectedness. We begin by casting a critical eye on wellbeing as a 'wicked problem,', providing the motivation for and context within which we have sought to develop our GENIAL theoretical framework.

\section{Problematising Health and Wellbeing}

The knowledge and practices of modern medicine are founded, organised and influenced by extreme mind-body dualism, an approach that constrains thinking and approaches to treatment, while contributing to scepticism of nonbiological explanations for illness such as social determinants. ${ }^{7}$ By contrast, the World Health Organisation appears to advocate for materialistic monism, referring to health as 'complete mental, physical and social wellbeing'. Professor Skrabanek reportedly joked that by this standard, health could only occur at the moment of mutual orgasm, ${ }^{8}$ pointing out that the WHO definition also constrains opportunities for whole health, especially for the increasing numbers of people who must live with a chronic condition. The limitations of these two competing approaches - extreme dualism vs materialistic monism - highlight the utility of what has been described as 'interactive dualism', emphasising an interaction between body and mind, a consideration that has implications for treating the "whole person' rather than a 'diseased body'. ${ }^{9}$ While research shows that people living with chronic conditions have tremendous potential for wellbeing, ${ }^{10,11}$ this potential is constrained by the pernicious impacts of social, economic and political power structures. This broader sociostructural context has led to a critique of wellbeing labelled as 'pollyannaism', ${ }^{12}$ referencing the fictional character Pollyanna, an orphan girl who played 'glad games' to manage loss and social prejudice. In this regard, neoliberalism - a dominant political and economic ideology in many parts of the world, especially in the west - has contributed to gross socioeconomic inequalities and inequities. ${ }^{13}$ Recent research has reported that neoliberal ideology increases the perception that one is in competition with others, increasing the sense of social isolation, which adversely impacts on individual wellbeing. ${ }^{14}$ Such ideology has contributed to a commercialisation of wellbeing (e.g. 'McMindfuness'), in which 'wellbeing' is stripped to its bare bones, and torn from its philosophical (and religious) foundations. This hijacking of wellbeing has led to criticisms arguing that 'positive psychology is for rich white people ${ }^{15}$ and that wellbeing is a casualty of modern consumer society. ${ }^{16}$

The climate emergency ${ }^{17}$ brings to light the glaring inconsistency between harnessing nature in service of individual health and wellbeing, while ignoring the impact of unrelenting business as usual, contributing to the unfolding climate catastrophe. ${ }^{18,19}$ Despite the economic slowdown associated with the COVID-19 pandemic, greenhouse gasses including carbon dioxide, methane and nitrous oxide have all set new records; Greenland and Antarctica show new all-time record low levels of ice mass; ocean heat content and acidification have set new records; and livestock numbers now represent more mass than humans and wild mammals combined. $^{17}$

These issues emphasise the considerable complexity surrounding the construct of wellbeing - a 'wicked problem'6 that is difficult to define and avoids straightforward solutions. When considered in a wider context - a systems context whole health cannot be achieved without planetary wellbeing, a concept recently defined as 'the highest attainable standard of wellbeing for human and non-human beings and their social and natural systems'.20 The newly coined concept of 'planetary wellbeing' is closely aligned with the United Nations Sustainable Development Goals (UNSDGs), which recognise that human wellbeing is unachievable unless the Earth's systems are preserved.

\section{Theoretical Innovations}

Psychological science is the discipline with which we are most familiar and are actively engaged; however, we have been inspired by and drawn on recent developments in the heterogeneous discipline of wellbeing science, characterised by a move beyond individual people, discipline, method and culture. $^{21}$ The impacts of the COVID-19 pandemic have reinforced the need to focus on self-transcendence, ${ }^{22}$ social identity ${ }^{23}$ and nature connectedness, ${ }^{24}$ and related reflections on how wellbeing might be promoted within the context of the unfolding climate catastrophe. ${ }^{25}$ Historically, psychological science has been restricted to individual wellbeing, but recent literature has emphasised interventions that target increasingly higher levels of scale beyond the individual including schools and universities (e.g. wellbeing literacy), workplaces (e.g. positive leadership), communities (e.g. volunteering, arts, culture, identities), cities (e.g. the 'happy city' initiative) and even nations (e.g. wellbeing public policy; UNSDGs). ${ }^{20,26}$ This work reflects efforts to support wellbeing through the development of nurturing environments at multiple levels and multidisciplinary contributions.

The recently proposed tridimensional model of behaviour, ${ }^{27}$ including personal (self-care), social (caring for others) and physical environment (caring for the environment) components - consistent with our own GENIAL framework - emphasises that individuals must first recognise and satisfy their own needs in order to be able to care for others and protect the environment. Therefore, initiatives to improve wellbeing at an individual level contribute to increased wellbeing at the community and environmental level. This model is also consistent with the recently proposed concept of 'planetary wellbeing', ${ }^{20}$ which encompasses three interconnected dimensions focused on individual (e.g. health, education, economic capacity and other elements required for a good life), social (including a focus on human rights, justice and grounds for a life of dignity and self-respect) and planetary dimensions, emphasising concern for the wellbeing of, in and for the planet. These multidisciplinary developments must now be synthesised in such a way that leads to 
interdisciplinarity and even transdisciplinary ways of working, ${ }^{28}$ in order to produce new knowledge and ultimately, more effective interventions to promote whole health. Social ecological models may provide a means to better understand the complexity of wellbeing, by placing the individual within their social and natural ecologies. ${ }^{5,29}$ The individual is positioned within increasing phenomenological scales, extending to the ecosystem and the life course, highlighting systemic influences on wellbeing that also change over time (i.e. the chronosystem). This temporal dimension was explicit in earlier iterations of our framework, ${ }^{3}$ while more recent iterations have emphasised the multi-levelled domains of wellbeing. ${ }^{18,19,30}$ Adopting a social ecological approach to wellbeing requires entrenched disciplinary and organisational silos to be overcome through silobusting techniques that include a focus on values, reward and development of people, collaboration and leadership. ${ }^{18,31}$

\section{Our Contributions to a Modern Science of Wellbeing}

The GENIAL model. The complexity of wellbeing motivated us to reflect on an extensive body of scholarly work. We were struck by research that had been developed in relative isolation from each other. For instance, positive psychological interventions (PPIs) ${ }^{32}$ are typically isolated from positive health behaviours, despite evidence indicating that such behaviours (e.g. physical activity) make an important contribution to positive psychological experience. ${ }^{33}$ We were also struck by the emergence of related work focusing on social identity to improve health and wellbeing, ${ }^{34}$ as well as increasing calls for a key role for psychology in managing the psychological consequences of the unfolding climate catastrophe. ${ }^{25,35}$ Yet, this body of work is isolated and has not been integrated into an overarching theory of wellbeing. These considerations motivated the development of the GENIAL framework ${ }^{3,18,19,30}$ (Table 1, Figure 1), which imposes an interpretative framework on the published literature, consistent with an abductive or explanatory approach to theory generation ${ }^{36}$ that addresses criticisms, controversies and conundrums that have plagued wellbeing science. An abductive approach helps to make sense of 'surprising, ambiguous or otherwise puzzling phenomena in order to fill the gaps in our beliefs, maintaining or restoring their coherence ${ }^{37}$ This developmental process led to the proposal of the GENIAL model, ${ }^{3,18,19,30}$ a life-course theoretical framework through which wellbeing is realised. GENIAL is a biopsychosocial framework that is explicitly linked to a broader context including sociostructural factors, the neglect of which have had major implications for interventions to promote (health and) wellbeing. The GENIAL acronym refers to relationships between Genomics-Environment-vagus Nerve-social Interaction-Allostatic regulation-Longevity. The word 'genial' also means 'friendly and cheerful' in English, reflecting the important impacts of social relationships and community on human health and wellbeing. Recent iterations of our framework ${ }^{18,19,30}$ have emphasised core domains across which any budding transdisciplinary model of wellbeing must embrace and transcend. These domains comprise the individual (including a balanced mind and a healthy body), community (social connectedness), the environment (connection with nature), positive societal change and sociostructural factors.

The capacity for individuals to promote their own wellbeing is much greater than their capacity to promote collective wellbeing, which is greater than the capacity to promote planetary wellbeing. Regardless of those constraints, there is tremendous scope for individuals themselves to promote individual wellbeing within each of those domains, alongside larger collaborative efforts (e.g. community partnerships; collaborative working across disciplines; activism) for successful adaptation to various societal challenges (e.g. burden of disease, climate change). We will now describe how we have started to apply this theory through the development of initiatives to promote whole health, laying foundations for wellbeing, positive change and societal transformation. Table 2 summarises a range of interventions that we have developed in partnership, describing how each intervention maps onto the core theoretical domains of our wellbeing framework.

\section{Application to Education}

A focus on wellbeing, broadly defined, in university student populations is important because students are a high-risk population for mental health conditions. Critically, levels of mental distress are increasing, and have been doing so even prior to the COVID pandemic. ${ }^{38}$ Depression and suiciderelated outcomes in university undergraduate students have a pooled prevalence of $21 \%,{ }^{39}$ which is considerably higher than the point prevalence estimate of depression in the general population, estimated at $12.9 \%{ }^{40}$ In response, we have developed a five-week module on wellbeing science that has been structured around the GENIAL framework. ${ }^{41,42}$ This module promotes a sense of connectedness to self (individual wellbeing), others (collective wellbeing) and nature (planetary wellbeing), consistent with social ecological theory. Students are introduced to the concept of 'sustainable' happiness and wellbeing, which has been defined in several different - yet complementary ways. Students learn how to 'sustain' improvements to wellbeing by drawing on theories of behaviour change ${ }^{43}$ while also placing happiness and wellbeing within the context of environmental 'sustainability', ${ }^{44}$ in which strategies to promote wellbeing do not involve the exploitation of other people, the environment or future generations. Students are encouraged to identify activities to promote their mental and physical wellbeing (through interventions to increase positive affect ${ }^{32}$ and/or positive health through, for example, physical activity ${ }^{33}$ ); community wellbeing (e.g. orientation to promote good $^{45}$ ) and 


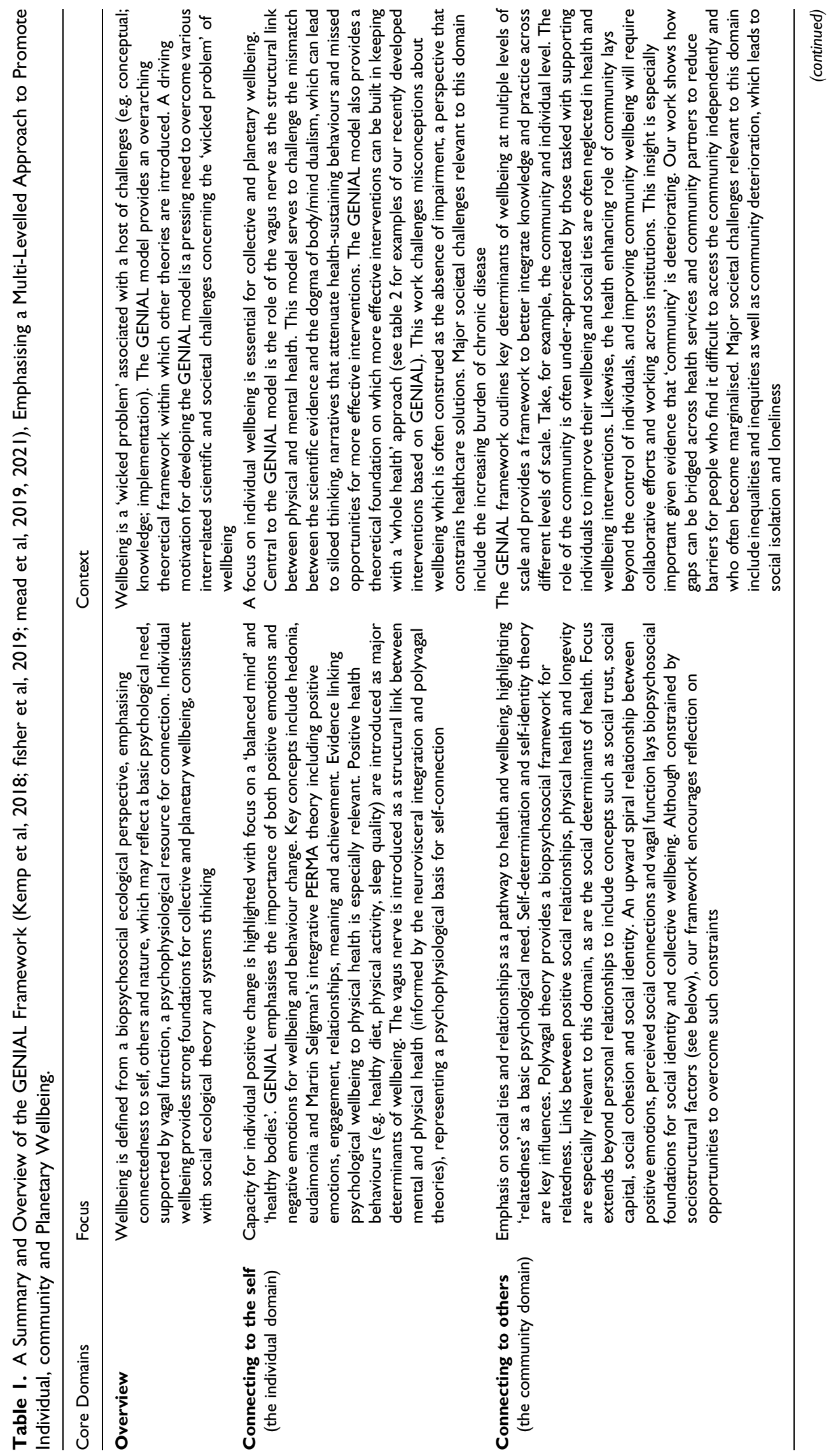




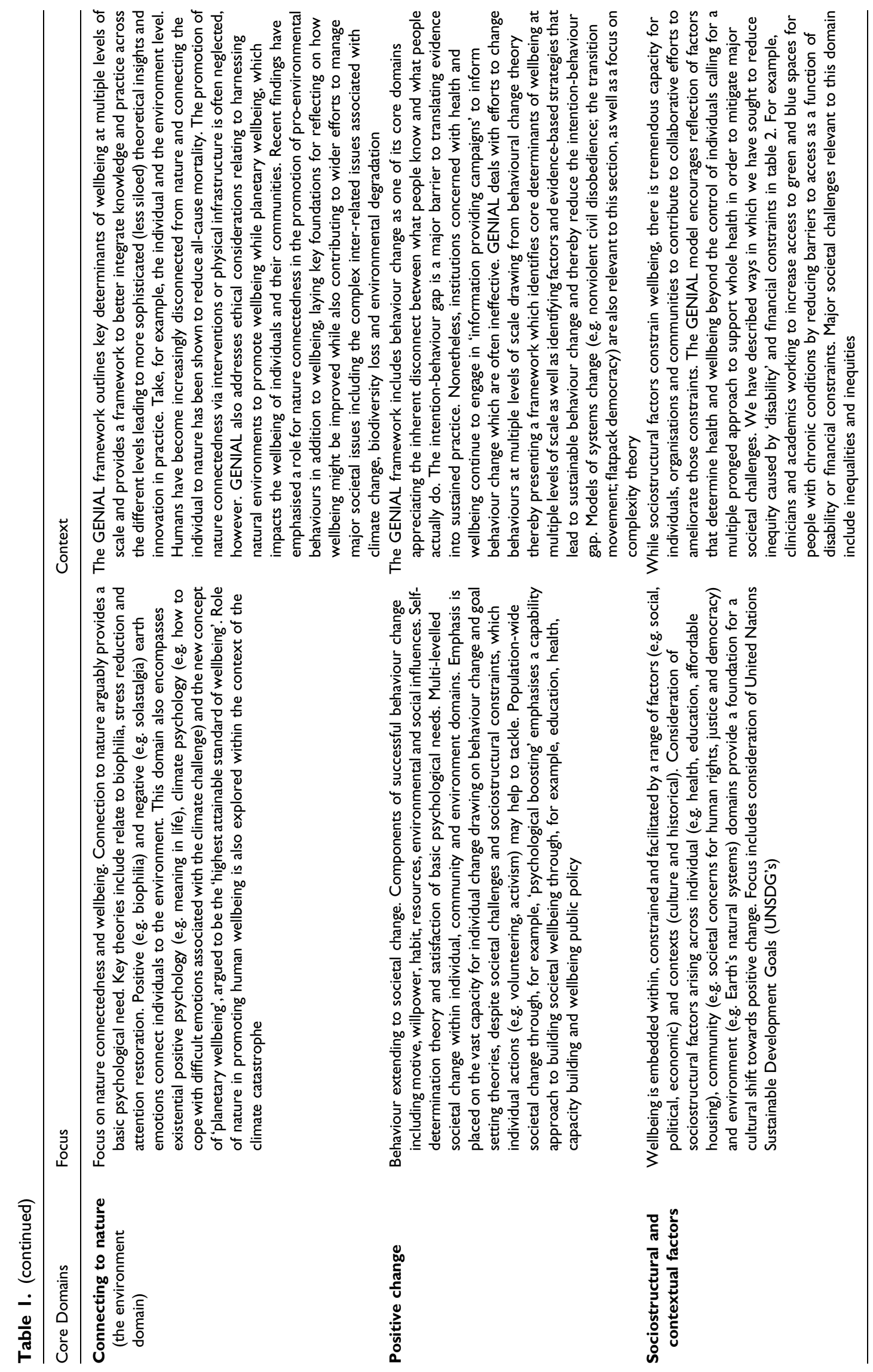




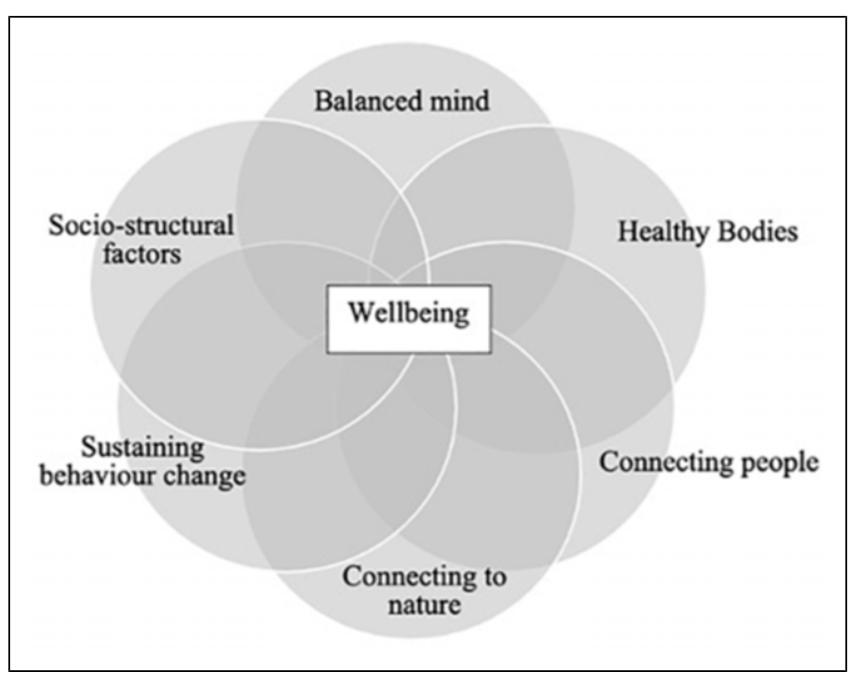

Figure I. Summary of the core theoretical components underpinning our interventions, integrating insights from psychological science with developments across multiple disciplines spanning the individual, community and the environment.

planetary wellbeing (e.g. nature-based mindfulness ${ }^{46}$ ) while reflecting on how they might work towards overcoming the many sociostructural constraints to wellbeing through, for example, contributions to social change (e.g. volunteering; civic engagement; activism) through commitment to something greater than oneself (i.e. self-transcendence). ${ }^{22}$ Wellbeing is therefore broadly defined and characterised by a focus on multi-levelled perspectives, ensuring that there is scope to improve the wellbeing of students themselves, while also encouraging students to reflect on how they might contribute to collective and planetary wellbeing, supporting efforts for positive societal change.

The impact of the intervention was evaluated during the COVID pandemic when university students faced a unique set of stressors. ${ }^{41}$ As well as individual student reports of impact, we have now reported promising group-wise evidence for the beneficial effects of our module on student wellbeing during the COVID-19 pandemic. ${ }^{41}$ This includes evidence from pre-post within-subject comparisons and convergent findings relating to comparisons with nationally representative samples. Together, these findings demonstrate the beneficial impact our module has had on student wellbeing during the COVID-19 pandemic. Emerging research has highlighted a variety of factors to have protected wellbeing during the pandemic, ${ }^{47}$ including tragic optimism, gratitude, meaning in life, physical health, social cohesion and identity and nature connectedness, all concepts that have been integrated into our module, amongst others. Importantly, we are continuously improving our module based on student feedback and recent developments in the field, consistent with an action research approach to curriculum development, professional development and a scholarly research agenda to improving wellbeing in university student populations. ${ }^{42}$
This process also led us to incorporate ideas on how individuals might contribute to positive societal change (e.g. volunteering; activism; psychological boosting) leading to further development of our theoretical model. (See Table 1 for summary of key principles). Our own findings together with those published in the wider literature highlight the capacity of the individual to promote their own wellbeing within the context of their lived environment, while also contributing to collective and planetary wellbeing. Although individuals play a relatively small role in improving collective and planetary wellbeing, adopting a relational approach to wellbeing by connecting to self, others and nature will be instrumental for driving much needed societal transformation in response to major societal challenges. Critically, 'bottom up' approaches will be rendered much more efficient if accompanied by 'top down' initiatives and strategies at multiple levels of scale, including, for example, community-led change (e.g. the Transition movement), policy-led change (e.g. Wellbeing Public Policy) and legislative-led change (Wellbeing for Future Generations Act).

\section{Application to Healthcare}

We recently described several factors that have constrained the long-term care of people living with chronic conditions ${ }^{30}$ including definitional issues focusing on complete mental, physical and social health, a goal that is seldom possible for people with long-term chronic conditions and inadequate models of healthcare including the 'acute medical model', which is underpinned by a 'find' and 'fix' deficit reduction approach that is incongruent with a 'whole health' approach because the absence of impairment is not representative of whole health. Cartesian dualism is often inherent in the way that health systems define, treat and design services which can lead to siloed thinking and narratives that actually attenuate health-sustaining behaviours. ${ }^{48}$ Factors such as these ultimately result in failure of public healthcare to meet the long-term needs of those living with chronic conditions. We have applied core principles from our GENIAL framework (Table 1) to inform a more holistic approach to the rehabilitation of people living with Acquired Brain Injury (ABI), in particular. This has involved designing more holistic models of health care within our clinical service and developing collaborations with community providers to bridge the gap between the health service and the community. This is needed as many people with chronic conditions struggle to access their local communities independently post-discharge, ${ }^{49}$ leading to social isolation and loneliness - major determinants of ill-health and premature mortality. ${ }^{3}$ We have now established a healthcare hub networked to the university and a wide range of local area initiatives that together better support sustainable community integration and wellbeing, in keeping with local top down initiatives advocating for a systems approach (i.e. A Regional Collaboration for Health, ARCH: http://arch.wales/en/index.htm). Table 2 summarises 


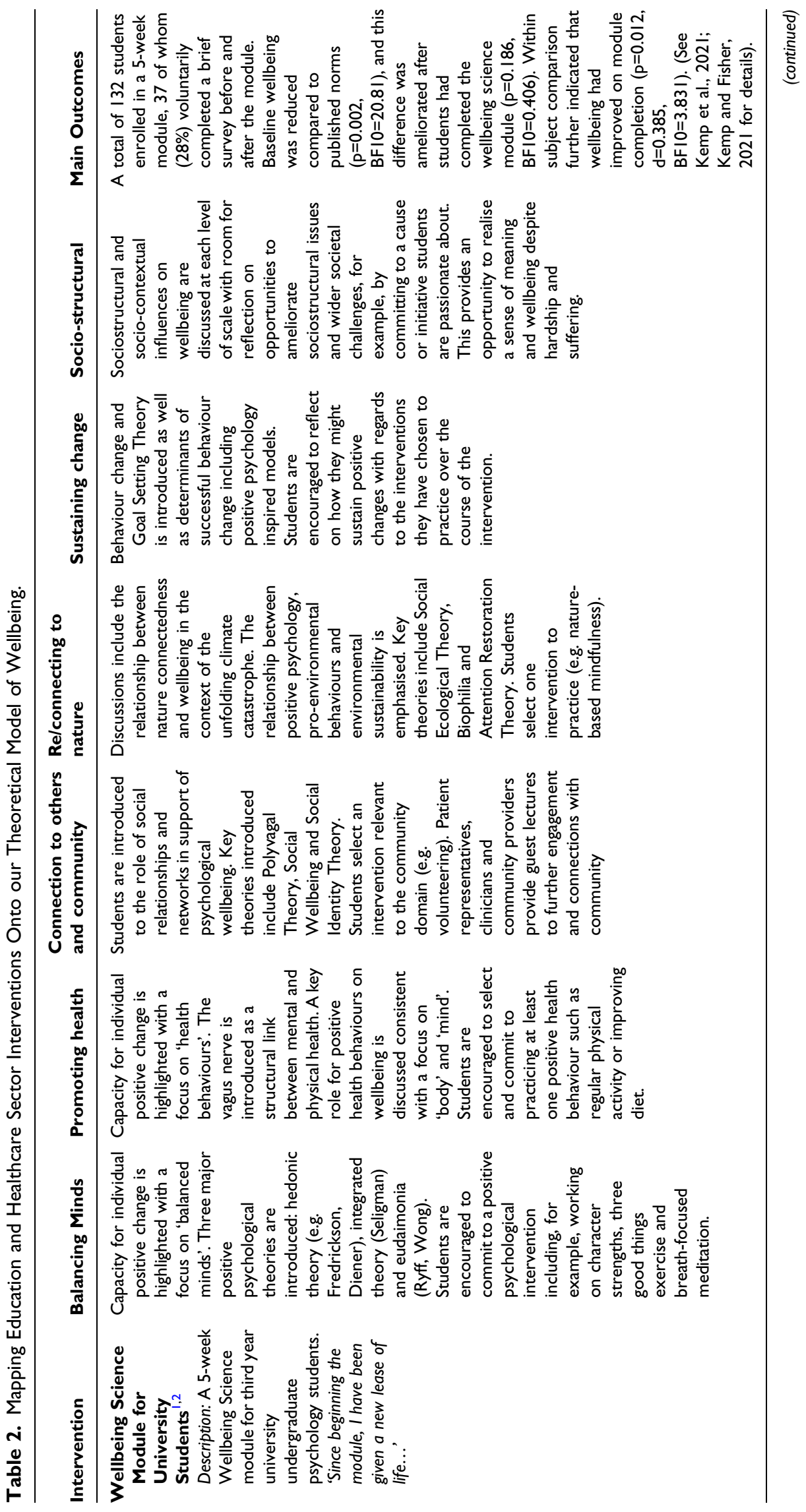




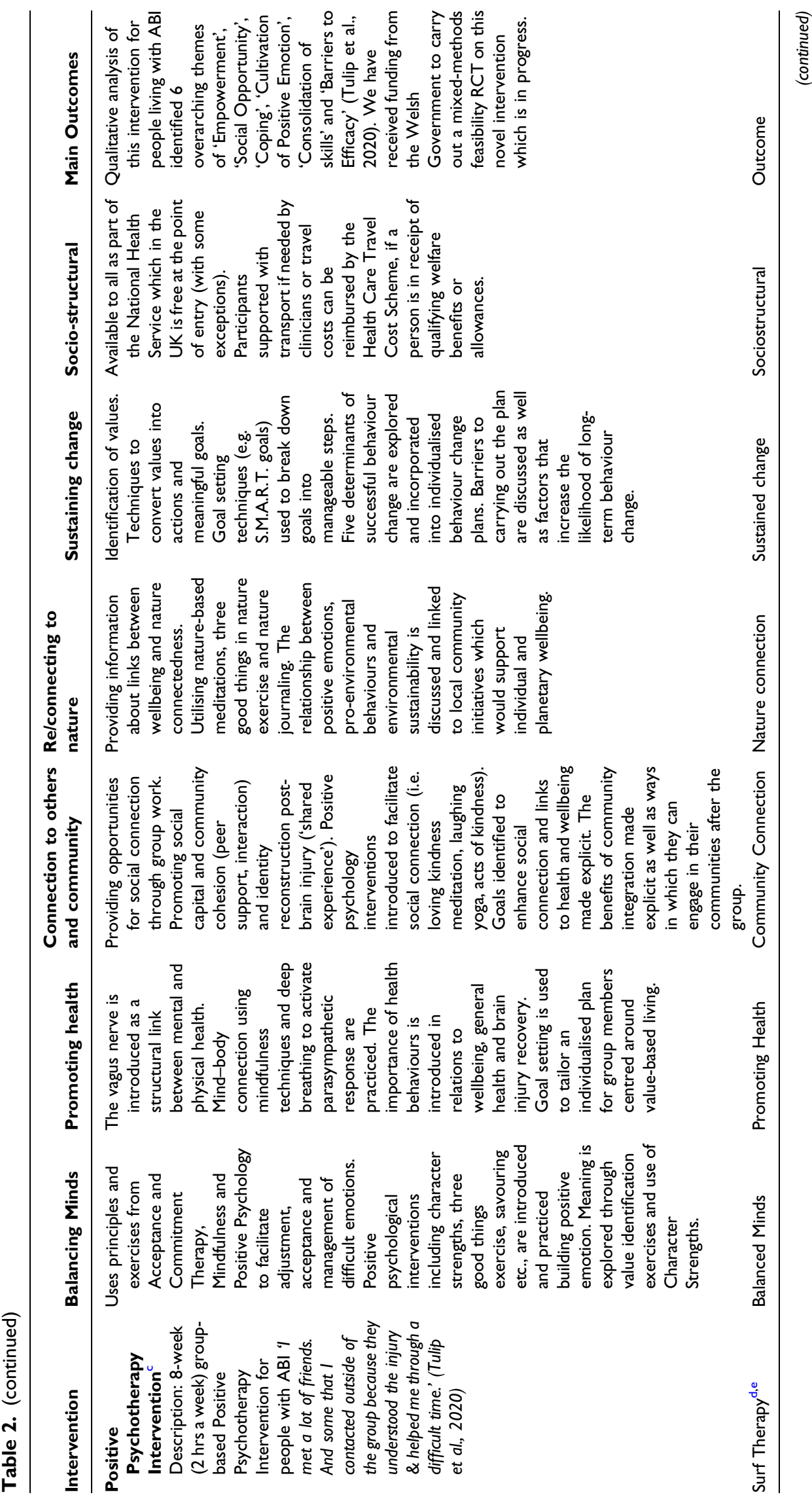


t-

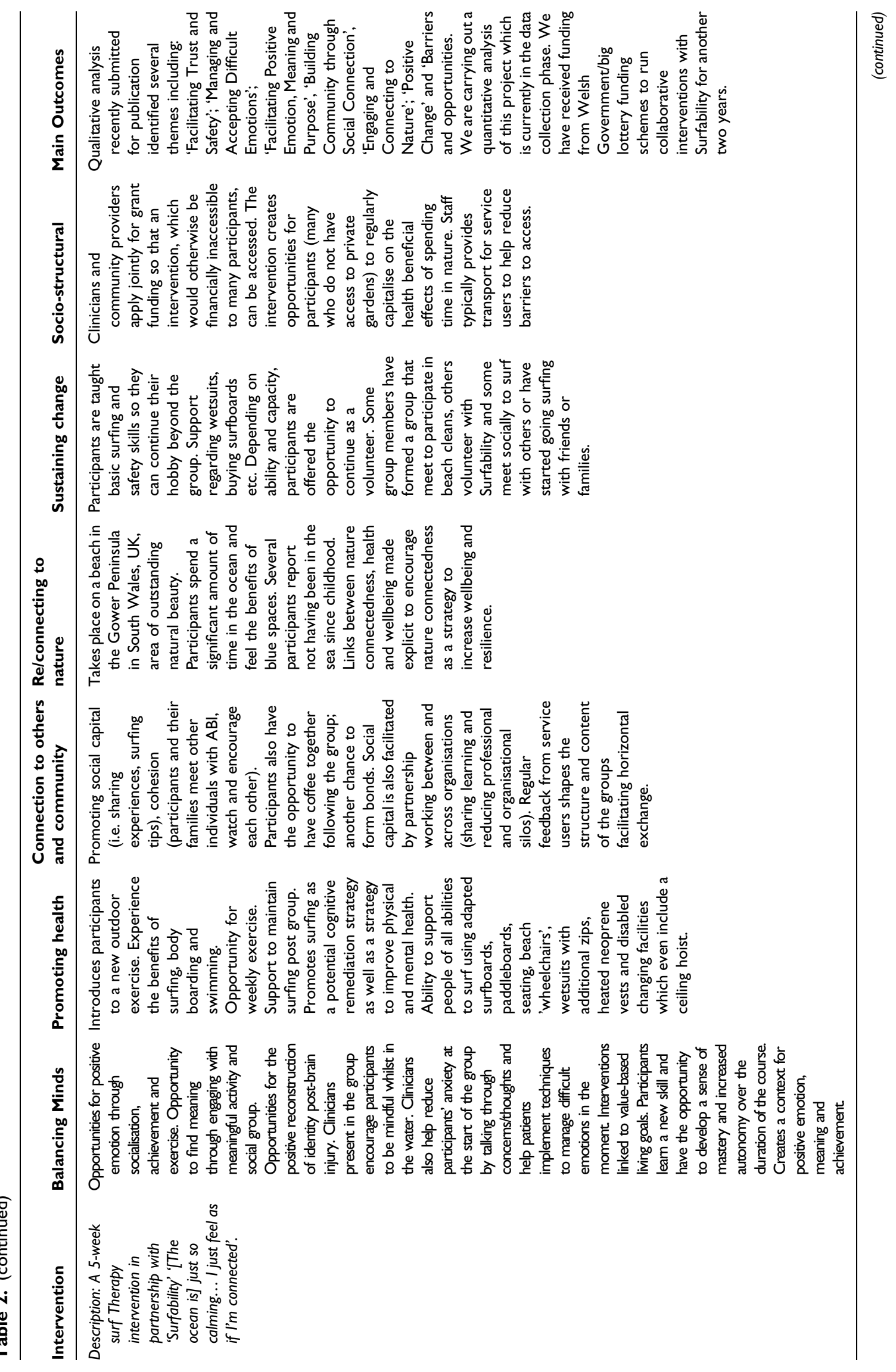




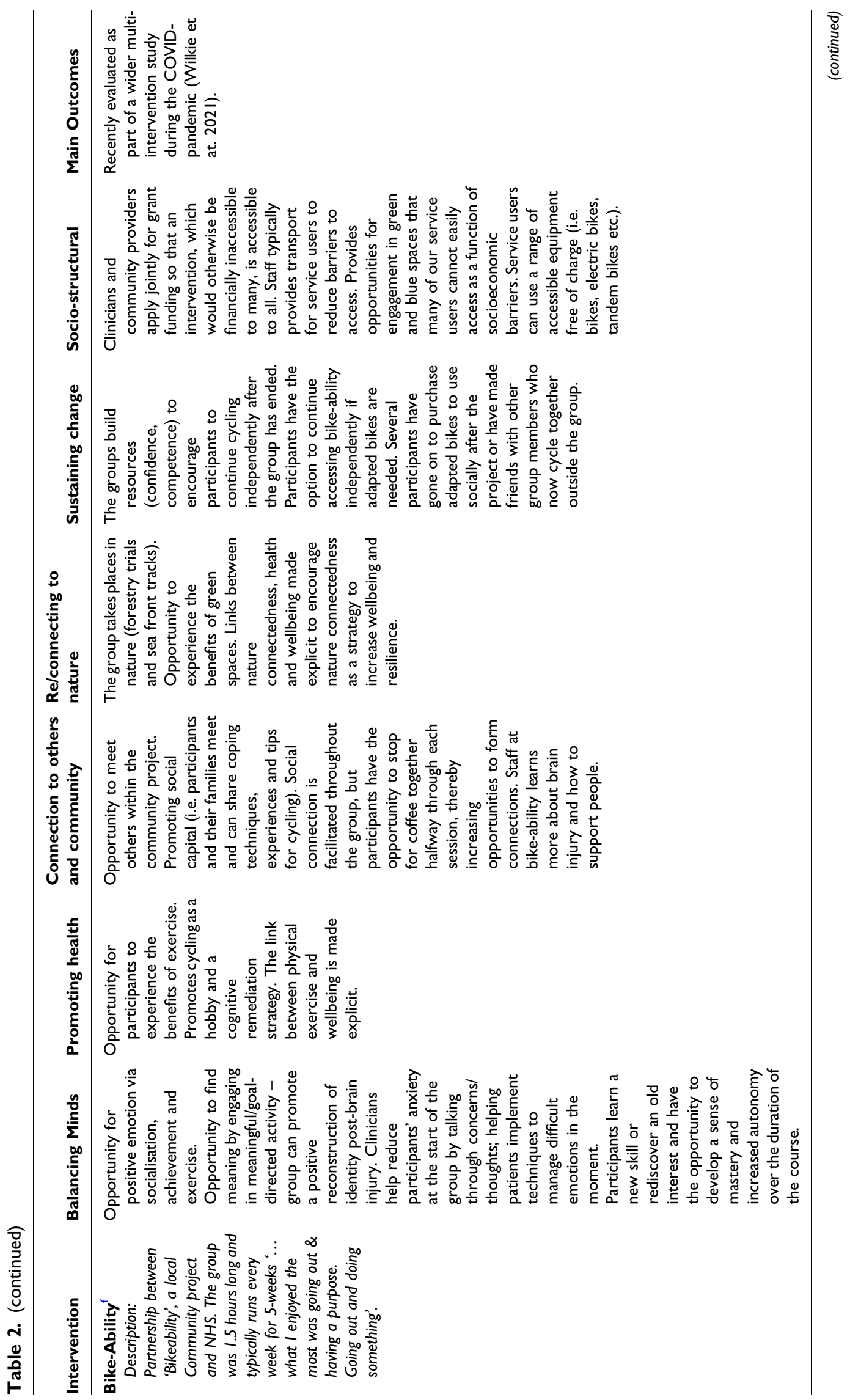




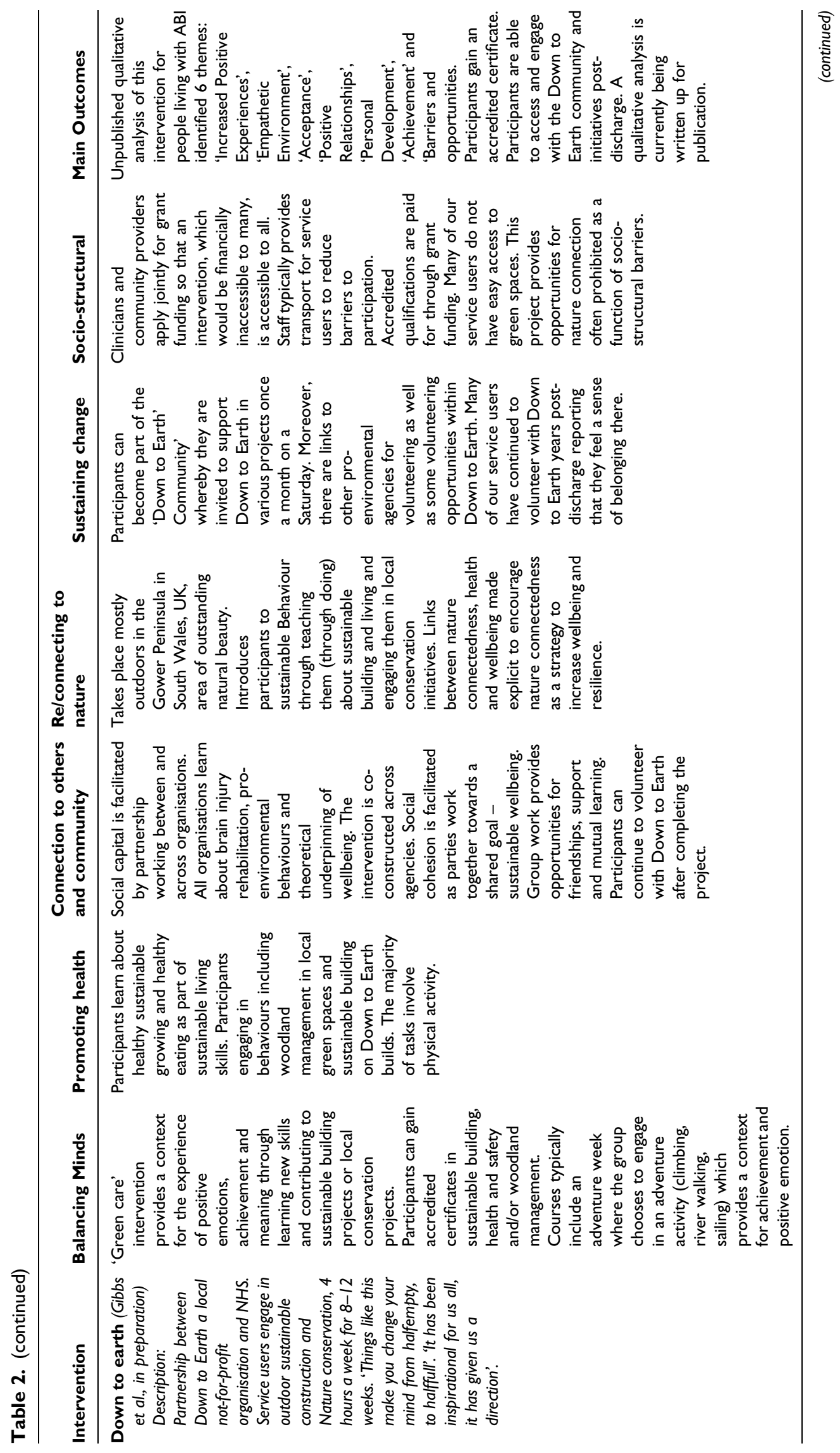




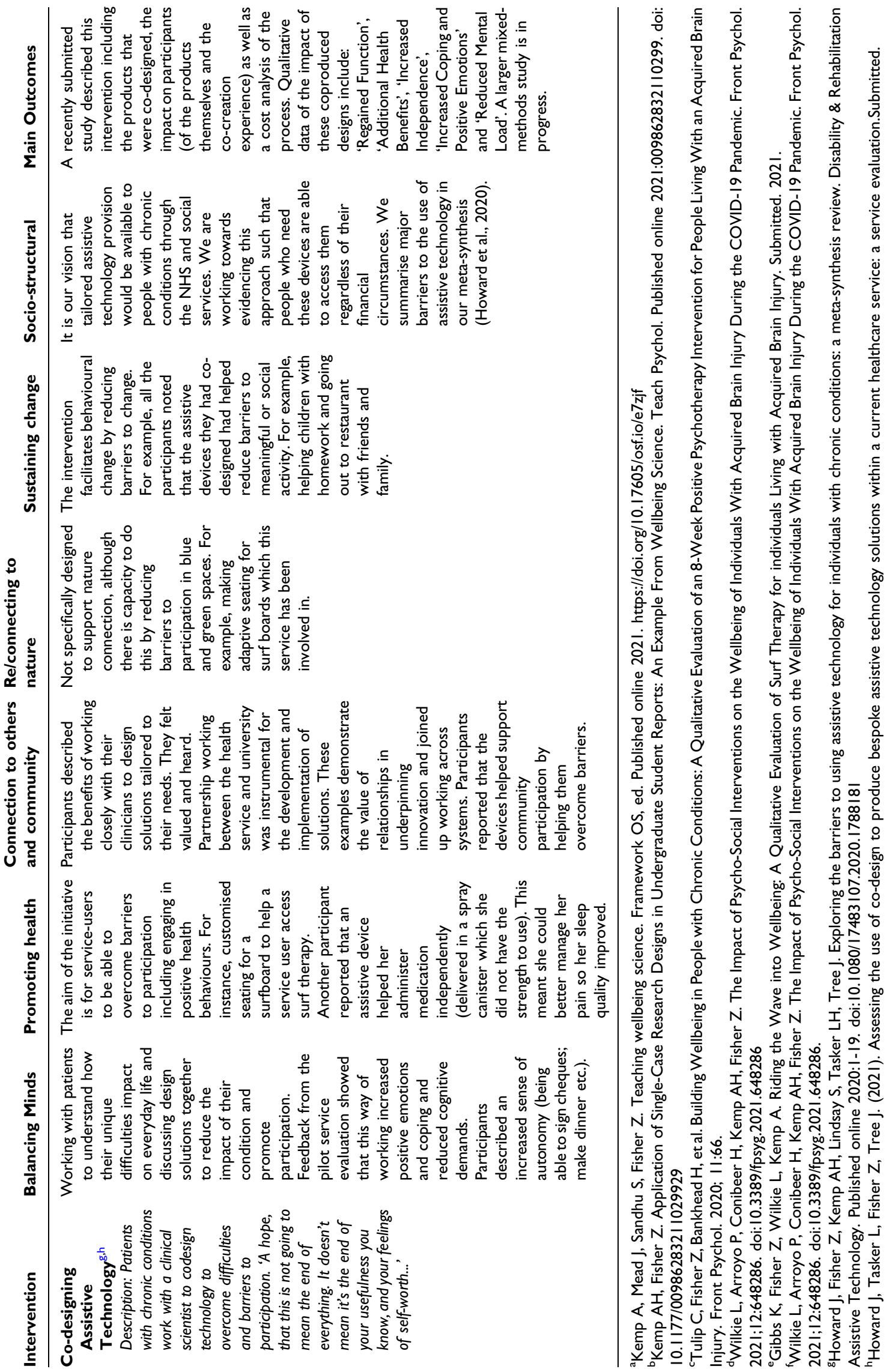




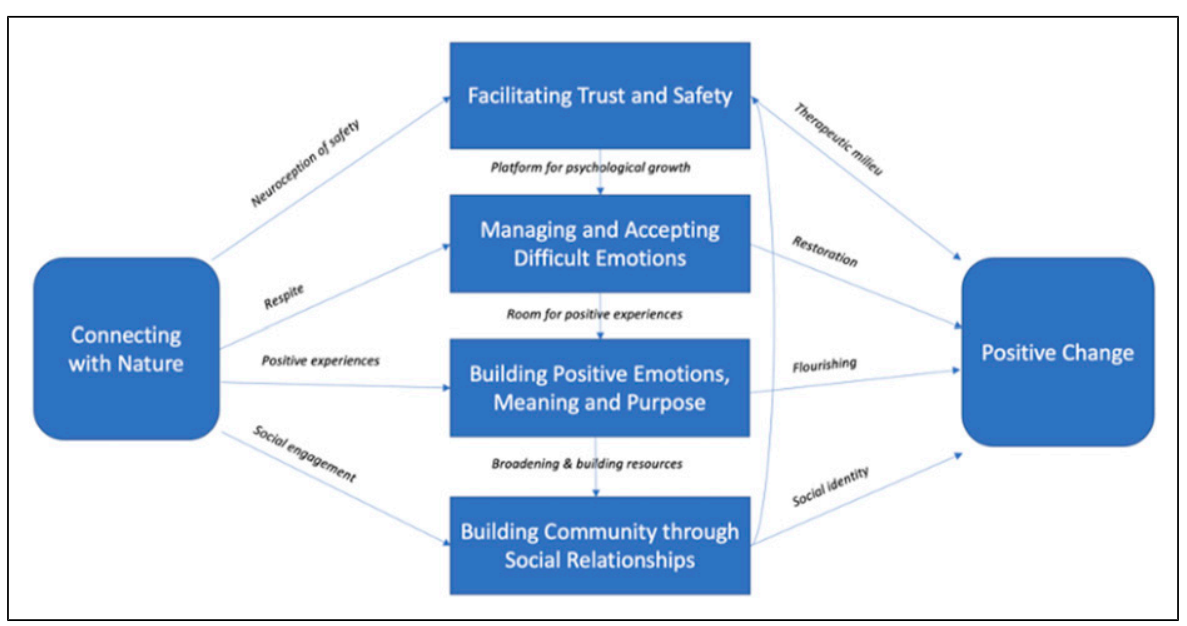

Figure 2. A proposed theoretical model for the benefits of surf therapy in people living with Acquired Brain Injury, illustrating potential relationships between identified themes and potential underlying mechanisms

hese initiatives which include positive psychotherapy, assistive technology co-design, nature-based exercise and local conservation projects. By means of example, we describe in more detail one of these initiatives: a Surf-Therapy collaboration between academics, clinicians, patients and the local Community Interest Company, Surfability (https:// surfabilityukcic.org). At an individual level, surf therapy involves explicitly promoting the benefits of exercise while clinicians work to facilitate feelings of positive emotion, meaning and achievement. At a community level, exercise provides a context for creating positive social relationships and eliciting feelings of belongingness and acceptance (social cohesion). Surf therapy brings together individuals with $\mathrm{ABI}$ (and their families) from diverse backgrounds, helping to promote (bonding and bridging) social capital and a strong social identity. At an environmental level, participants are engaged in nature-based exercise, facilitating the experience of wellbeing, which has also been shown to promote the emergence of pro-environmental behaviours. ${ }^{50}$ Mindful of the need to overcome sociostructural constraints to participation, clinicians and community providers have secured competitive grant funding to develop and deliver an intervention that would otherwise be inaccessible to many participants. Figure 2 provides a theoretical model for the benefits of surf therapy in people living with $\mathrm{ABI}$, illustrating relationships between identified themes from unpublished qualitative analysis and potential underlying mechanisms identified from the available literature.

\section{Discussion and Conclusion}

We have sought to promote 'whole health' in a coordinated way by moving from theory to application and back to theory. Our work in the education sector has focused on building wellbeing in university students, providing opportunities to flourish through connections to self, others and nature, and a commitment to something greater than oneself (i.e. selftranscendence). ${ }^{22}$ Our service evaluation work demonstrates how new interventions based on our theoretical framework have been translated into clinical practice and tailored to meet the needs of specific populations, providing opportunities for the experience of multiple determinants of wellbeing despite life changing conditions. Evaluations of our interventions have helped to refine our model, and these refinements subsequently led to further improvements in interventions themselves, through co-creation, abduction and action research methods.

Our GENIAL framework has helped to frame and contextualise the construct of wellbeing, laying the foundations for thinking differently about how 'whole health' might be promoted by reflecting on individual, collective and planetary wellbeing. We have been inspired by recent developments in wellbeing science including a move beyond individual people, discipline, method and culture, encompassing developments in psychological science, ${ }^{21}$ wellbeing public policy ${ }^{51}$ and the pursuit of sustainable development goals in higher education. ${ }^{20}$ Our GENIAL model has provided a useful framework for reflecting on action at multiple levels, that include the individual, but also extend into what Bronfenbrenner described as the 'exosystem', which refers to settings or structures that function independently of the individual, but that nevertheless impact on settings in which the individual lives.

In conclusion, we have argued that wellbeing plays a key role in 'whole' health and have shown how the GENIAL framework provides a strong basis on which health and wellbeing might be improved at multiple levels of scale in a just and sustainable way. Our work has involved: 1) developing a theoretical framework (the GENIAL model) to better frame our understanding of the complexity of wellbeing and develop novel interventions, 2) identifying funding and collaborative opportunities across organisations and disciplines to overcome barriers and practical challenges, 3) cocreating and co-delivering innovative interventions alongside community partners, 4) evaluating outcomes through multipronged research methods to inform continued refinement of our framework and interventions and 5) engaging with 
multiple stakeholders. This work provides a step toward a transdisciplinary model of wellbeing and way of working that has facilitated a reimagining of what it means to experience health and wellbeing, which often includes hardship and great suffering.

\section{Acknowledgements}

We would like to thank our PhD Students, Jessica Mead, Katie Gibbs, Jonathan Howard, Lowri Willkie and Sanjeev Sandu whose work as part of our GENIAL science team has contributed to our knowledge and thinking. We would like to thank our colleagues at Swansea University, Swansea Bay University Health Board and Fieldbay Ltd, who have co-funded our $\mathrm{PhD}$ students and recognised and promoted our work through various awards including the University Research and Innovation Award for Outstanding Impact on Health and Wellbeing (2018), the Swansea Bay University Health Board Chairman's VIP Award for Commitment to Research and Learning (2018) and Swansea University Morgan Advanced Studies Institute (MASI) Summer of Hope Award (2021) to host a 2-day student-led wellbeing symposium. Finally, we would like to express our heartfelt thanks for the support of our service users, students and community partners who have worked with us and given so much of their time and energy to support our research agenda.

\section{Declaration of Conflicting Interests}

The author(s) declared no potential conflicts of interest with respect to the research, authorship, and/or publication of this article.

\section{Funding}

The author(s) disclosed receipt of the following financial support for the research, authorship, and/or publication of this article: We have built a novel and innovative positive psychotherapy intervention that is based on our GENIAL theoretical framework. This intervention was supported by grant funding from the Health and Care Research Wales through the Research for Public Patient Benefit Scheme (RfPPB-18-1502).

\section{ORCID iDs}

Andrew H Kemp (D) https://orcid.org/0000-0003-1146-3791

Zoe Fisher (D) https://orcid.org/0000-0001-8150-2499

\section{References}

1. Diener E, Chan MY. Happy people live longer: subjective wellbeing contributes to health and longevity. Appl Psychol: Health and Well-Being. 2011;3(1):1-43. doi:10.1111/j.1758-0854. 2010.01045.x.

2. Kemp AH, Quintana DS. The relationship between mental and physical health: Insights from the study of heart rate variability. Int J Psychophysiol. 2013;89:288-296. DOI: 10.1016/j. ijpsycho.2013.06.018.

3. Kemp AH, Arias JA, and Fisher Z. Social ties, health and wellbeing: a literature review and model. In: Ibáñez, A, Sedeño, L, García A, (eds). Neuroscience and Social Science, The
Missing Link. New York, NY: Springer International Publishing; 2017:Vol 59, 397-427.

4. Bronfenbrenner U. Toward an experimental ecology of human development. Am Psychol. 1977;32(7):513-531. doi:10.1037/ 0003-066x.32.7.513.

5. Lomas T. Positive Social Psychology: A Multilevel Inquiry Into Sociocultural Well-Being Initiatives. Psychol Publ Pol Law. 2015;21(3):338-347. doi:10.1037/law0000051.

6. Bache I, Reardon L, Anand P. Wellbeing as a Wicked Problem: Navigating the Arguments for the Role of Government. $J$ Happiness Stud. 2016;17(3):893-912. doi:10.1007/s10902015-9623-y.

7. Berkman LF. Social Epidemiology: Social Determinants of Health in the United States: Are We Losing Ground? Annu Rev Publ Health. 2009;30(1):27-41. doi:10.1146/annurev. publhealth.031308.100310.

8. Smith R. The end of disease and the beginning of health. 2008 . https://blogs.bmj.com/bmj/2008/07/08/richard-smith-the-endof-disease-and-the-beginning-of-health/. Acessed April 25, 2019.

9. Switankowsky I. Dualism and its Importance for Medicine. Theor Med Bioeth. 2000;21(6):567-580. doi:10.1023/a: 1026570907667.

10. Tulip C, Fisher Z, Bankhead H, et al. Building Wellbeing in People With Chronic Conditions: A Qualitative Evaluation of an 8-Week Positive Psychotherapy Intervention for People Living With an Acquired Brain Injury. Front Psychol. 2020;11: 66. doi:10.3389/fpsyg.2020.00066.

11. Wilkie L, Arroyo P, Conibeer H, Kemp AH, Fisher Z. The Impact of Psycho-Social Interventions on the Wellbeing of Individuals With Acquired Brain Injury During the COVID-19 Pandemic. Front Psychol. 2021;12:648286. doi:10.3389/fpsyg. 2021.648286.

12. Yakushko O. Scientific Pollyannaism, From Inquisition to Positive Psychology. Published online; 2019. 10.1007/978-3030-15982-5.

13. Ostry JD, Loungani P, Furceri D. Neoliberalism: Oversold? Finance Dev. 2016;53(2).

14. Becker JC, Hartwich L, Haslam SA. Neoliberalism can reduce well-being by promoting a sense of social disconnection, competition, and loneliness. Br J Soc Psychol. 2021;60(3): 947-965. doi:10.1111/bjso.12438.

15. Coyne JC. Positive psychology is mainly for rich white people. 2013. https://www.coyneoftherealm.com/2013/08/21/positivepsychology-is-mainly-for-rich-white-people/ Accessed August 6, 2021.

16. Carlisle S, Henderson G, Hanlon PW. 'Wellbeing': A collateral casualty of modernity? Soc Sci Med. 2009;69(10):1556-1560. doi:10.1016/j.socscimed.2009.08.029.

17. Ripple WJ, Wolf C, Newsome TM, et al. World scientists' warning of a climate emergency 2021. Bioscience. 2021;71: 894-898. doi:10.1093/biosci/biab079.

18. Mead J, Fisher Z, Kemp AH. Moving Beyond Disciplinary Silos Towards a Transdisciplinary Model of Wellbeing: An 
Invited Review. Front Psychol. 2021;12:12. doi:10.3389/fpsyg. 2021.642093.

19. Mead J, Fisher Z, Wilkie L, et al. Rethinking Wellbeing: Toward a More Ethical Science of Wellbeing that Considers Current and Future Generations. Published online; 2019. 10.22541/au. 156649190.08734276.

20. Antó JM, Martí JL, Casals J, et al. The Planetary Wellbeing Initiative: Pursuing the Sustainable Development Goals in Higher Education. Sustainability. 2021;13(6):3372. doi:10. 3390/su13063372.

21. Lomas T, Waters L, Williams P, Oades LG, Kern ML. Third wave positive psychology: broadening towards complexity. $J$ Posit Psychol. 2020;16:660-674. doi:10.1080/17439760.2020. 1805501. Published online.

22. Wong PTP, Arslan G, Bowers VL, et al. Self-Transcendence as a Buffer Against COVID-19 Suffering: The Development and Validation of the Self-Transcendence Measure-B. Front Psychol. 2021;12:648549. doi:10.3389/fpsyg.2021.648549.

23. Jetten J, Reicher SD, Haslam SA, Cruwys T, eds Together Apart: The Psychology of COVID-19. New York, NY: Sage Publications Ltd; 2020.

24. Richardson M, Hamlin I. Nature engagement for human and nature's well-being during the Corona pandemic. J Publ Ment Health. 2021;20(2):83-93. doi:10.1108/jpmh-022021-0016.

25. Bendell J. Psychological insights on discussing societal disruption and collapse. Ata: Journal of Psychotherapy Aotearoa New Zealand. 2021;25(1):45-63. doi:10.9791/ajpanz. 2021.05.

26. Waters L, Cameron K, Nelson-Coffey SK, et al. Collective wellbeing and posttraumatic growth during COVID-19: how positive psychology can help families, schools, workplaces and marginalized communities. J Posit Psychol. 2021:1-29. doi:10. 1080/17439760.2021.1940251.

27. Corral-Verdugo V, Pato C, Torres-Soto N. Testing a tridimensional model of sustainable behavior: self-care, caring for others, and caring for the planet. Environ Dev Sustain. 2021; 23(9):12867-12882. doi:10.1007/s10668-020-01189-9.

28. Choi B, and Pak A. Multidisciplinarity, Interdisciplinarity and Transdisciplinarity in Health Research, Services, Education and Policy: 1. Definitions, Objectives, and Evidence of effectiveness. Clin Invest Med 2006;29(6):351-364.

29. Nielsen TW, Ma JS. Connecting Social and Natural Ecologies Through a Curriculum of Giving for Student Wellbeing and Engagement. Aust J Environ Educ. 2018;34(3):215-227. doi: 10.1017/aee.2018.41.

30. Fisher Z, Galloghly E, Boglo E, Gracey F, Kemp AH. Emotion, Wellbeing and the Neurological Disorders. In: Reference Module in Neuroscience and Biobehavioral Psychology. 2nd ed. Amsterdam, Netherlands: Elsevier; 2022:220-234. doi:10. 1016/b978-0-12-819641-0.00013-x.

31. de Waal Ade, Weaver M, Day T, van der Heijden B. SiloBusting: Overcoming the Greatest Threat to Organizational Performance. Sustainability. 2019;11(23):6860. doi:10.3390/ su11236860.
32. Carr A, Cullen K, Keeney C, et al. Effectiveness of positive psychology interventions: a systematic review and metaanalysis. J Posit Psychol. 2020;16:749-769. doi:10.1080/ 17439760.2020.1818807. Published online.

33. Buecker S, Simacek T, Ingwersen B, Terwiel S, Simonsmeier BA. Physical activity and subjective well-being in healthy individuals: a meta-analytic review. Health Psychol Rev. 2020; 15:574-592. doi:10.1080/17437199.2020.1760728.

34. Haslam C, Jetten J, Cruwys T, Dingle G, Haslam A. The New Psychology of Health: Unlocking the Social Cure. New York, NY: Routledge; 2017. https://www.routledge.com/The-NewPsychology-of-Health-Unlocking-the-Social-Cure/HaslamJetten-Cruwys-Dingle-Haslam/p/book/9781138123885.

35. Corral-Verdugo V. Psychology of climate change (Psicología del cambio climático). Psyecology. 2021;12(2):254-282. doi: 10.1080/21711976.2021.1901188.

36. Haig BD. An Abductive Theory of Scientific Method. Psychol Methods. 2005;10(4):371-388. doi:10.1037/1082-989x.10.4.371.

37. Żelechowska D, Żyluk N, Urbański M. Find out a new method to study abductive reasoning in empirical research. Int J Qual Methods. 2020;19:160940692090967. doi:10.1177/ 1609406920909674.

38. Twenge JM, Cooper AB, Joiner TE, Duffy ME, Binau SG. Age, period, and cohort trends in mood disorder indicators and suicide-related outcomes in a nationally representative dataset, 2005-2017. J Abnorm Psychol. 2019;128(3):185-199. doi:10. 1037/abn0000410.

39. Sheldon E, Simmonds-Buckley M, Bone C, et al. Prevalence and risk factors for mental health problems in university undergraduate students: A systematic review with meta-analysis. J Affect Disord. 2021;287:282-292. doi:10.1016/j.jad.2021.03. 054.

40. Lim GY, Tam WW, Lu Y, Ho CS, Zhang MW, Ho RC. Prevalence of Depression in the Community from 30 Countries between 1994 and 2014. Sci Rep. 2018;8(1):2861. doi:10.1038/ s41598-018-21243-x.

41. Kemp AH, Mead J, Sandhu S, Fisher Z. Teaching Wellbeing Science. Open Science Framework. Published online; 2021. doi:10.17605/osf.io/e7zjf.

42. Kemp AH, Fisher Z. Application of single-case research designs in undergraduate student reports: an example from wellbeing science. Teaching of Psychology. 2021:009862832110299. Published online 2021. doi:10.1177/00986283211029929.

43. Sheldon KM, Lyubomirsky S. Revisiting the Sustainable Happiness Model and Pie Chart: Can Happiness Be Successfully Pursued? J Posit Psychol. 2019;16:145-154. doi:10.1080/ 17439760.2019.1689421.Published online

44. O'Brien C. Education for Sustainable Happiness and WellBeing. New York, NY: Routledge. Published online; 2016. doi: 10.4324/9781315630946.

45. Weziak-Bialowolska D, Bialowolski P, VanderWeele TJ, McNeely E. Character strengths involving an orientation to promote good can help your health and well-being. evidence from two longitudinal studies. Am J Health Promot. 2020;35; 388-398. doi:10.1177/0890117120964083. 
46. Djernis L, Lerstrup S, Poulsen O'T, Stigsdotter fnm, Dahlgaard fnm, O'Toole fnm. A systematic review and meta-analysis of nature-based mindfulness: effects of moving mindfulness training into an outdoor natural setting. Int J Environ Res Publ Health. 2019;16(17):3202. doi:10.3390/ijerph16173202.

47. Mead JP, Fisher Z, Tree JJ, Wong PTP, Kemp AH. Protectors of wellbeing during the COVID-19 pandemic: key roles for gratitude and tragic optimism in a UK-based cohort. Front Psychol. 2021;12:647951. doi:10.3389/fpsyg.2021.647951.

48. Burgmer P, Forstmann M. Mind-Body Dualism and Health Revisited. Soc Psychol. 2018;49(4):219-230. doi:10.1027/ 1864-9335/a000344.
49. Mahar C, Fraser K. Barriers to successful community reintegration following acquired brain injury (ABI). Int $J$ Disabil Manag. 2011;6(1):49-67. doi:10.1375/jdmr.6.1.49.

50. Martin L, White MP, Hunt A, Richardson M, Pahl S, Burt J. Nature contact, nature connectedness and associations with health, wellbeing and pro-environmental behaviours. J Environ Psychol. 2020;68:101389. doi:10.1016/j.jenvp. 2020.101389.

51. Fabian M, Pykett J. Be happy: navigating normative issues in behavioral and well-being public policy. Perspect Psychol Sci. 2021:174569162098439. doi:10.1177/1745691620984395. Published online. 